\title{
CONSUMER PREFERENCES FOR FRONT-OF-PACK NUTRITION LABELS: THE CASE OF NUTRI-SCORE LABELLING IN SPAIN.
}

\author{
Niculina Iudita Sampalean $^{\text {a }}$, Daniele Rama a ${ }^{\text {, Tiziana de-Magistris }}{ }^{\text {b, c* }}$ \\ a Departamento de Economía Agroalimentaria, Facultad de Ciencias Agrarias, Alimentarias y \\ Ambientales, Campus Piacenza-Cremona, Universidad Católica del Sagrado
} Corazón, via Emilia Parmense, 84, 29122 Piacenza (PC), Italia

${ }^{b}$ Centro de Investigación y Tecnología Agroalimentaria de Aragón (CITA), Unidad de Economía Agroalimentaria y de los Recursos Naturales. Saragossa 50013, Spain

${ }^{c}$ Instituto Agroalimentario de Aragón (IA2), CITA-Universidad de Zaragoza Saragossa 50059, Spain

* Correspondence: tmagistris@ cita-aragon.es; Tel.: +34-976-71-6352

\begin{abstract}
In Europe, in the Farm to Fork Strategy (FTFS), published on 20 May 2020, has been indicated for the 2022 the harmonization of all nutritional labelling introduced by European countries voluntarily, following the art 35 of the Regulation 1196/2011. Actually, different countries have introduced front-of-pack nutrition labels (FoPNL) as a tool to help their citizens to make healthy decisions when shopping. For example, Nutri-Score has already been endorsed by a number of European countries, Spain being the second country adopting it (2018) and rejected by some others, like Italy that claims it penalizes Made in Italy food products, especially the EU quality certified. This study analyses Spanish consumer's choices and understanding of Nutri-Score, NutrInform Battery and Multiple Traffic Light. 400 Spanish consumers participated in an online survey during the fall 2020 and a Discrete Choice Experiment was implemented (DCE). The primarily analysis indicate that Spanish consumers value positively the FoPNL, but NutriScore was not preferred as the best option since the most valued was the NutrInform Battery.
\end{abstract}

Keywords: Grana Padano PDO, generic Grana, Nutritional labels, FoPNL, Choice Experiment.

\section{Introduction and objectives}

Chronic non-communicable diseases (NCDs) create one of the greatest pressures to public health and economic growth at locally, nationally, and globally. Obesity, cardiovascular diseases (CVD), cancer, and diabetes are responsible for 35 million deaths and $60 \%$ of all deaths every year globally. The Regulation $1169 / 2011$ in its article 35 section 5, reports that it is approved (voluntarily), to repeat on the front of the container certain nutritional information (energy value, fats, saturated fatty acids, sugars, and salt). Hence, different countries have introduced front-of-pack nutrition labels (FoPNL) as a tool to help their citizens to make healthy decisions when shopping. In this sense Spain adopted the Nutri-Score, also known as the 5-Colour Nutrition label or 5-CNL (Julia and Hercberg, 2017) is a nutritional rating system that was selected by the French government in March 2017 to be displayed on food products after it was compared against several labels proposed by industry or retailers. However, some European countries such as Italy has preferred to create an alternative voluntary FoPNL, the NutrInform Battery labelling arguing that it mostly disadvantages the Made in Italy food products.

Before its adoption in Spain, different studies were carried out in order to see which FoPNL would work best for its population (Galan et al. 2019, Goiana-da-Silva et al.,2019, , Talati et al 2019) but those studies did not include the NutrInform Battery, the Italian proposed FoPNL and no studies has been conducted in Spain yet.

Hence, the objective of the present study is to analyse Spanish consumer's choices and understanding of both earlier mentioned FoPL together with the United Kingdom's one, the Multiple Traffic Light.

\section{Methodology}




\subsection{The survey}

In the fall of 2020, a total of 400 Spanish consumers participated in an online survey that used a Discrete Choice Experiment. The survey was then distributed online by a market research agency and the respondents were randomly selected using the probability proportional to size (PPS), with the sample being stratified by age and sex.

\subsection{DCE: Product and attribute selection}

The product used in this study to investigate consumers' willingness to pay for different FoPNL was cheese. We selected a 250 grams package of generic grana cheese due to its great popularity in the cheese market and its acquisition regularity by consumers. To establish the price levels, information on the grana cheese type sold in different supermarkets was used, and four price levels were then established. For the 'FoPNL', four levels were established: 'no label' 'Nutri-Score''NutrInform Battery' 'Multiple Traffic light', the 'PDO' certification had two levels, indicating that the grana cheese carried the PDO certification or not. The attributes selected and their levels are summarised in Table 1.

Using the Software Ngene ${ }^{\text {TM }}$ we created a fractional factorial design with a D-efficiency of $98 \%$ and 12 possible choice tasks that were shown to each respondent. Each choice task consisted of two product alternatives and a no-buy option. In the choice experiment respondents were asked to make repeated choices between two cheese products and a no-purchase alternative. The cheese was described by the following attributes as describe in table 1.

Table 1. Attributes and attributes levels used in the choice experiment

\begin{tabular}{|c|c|c|}
\hline Attribute & Attribute Levels & Description \\
\hline \multirow{3}{*}{$\begin{array}{l}\text { PDO } \\
\text { Certification }\end{array}$} & $\begin{array}{l}\text { PDO certified (Grana } \\
\text { Padano })\end{array}$ & The cheese pack is Grana Padano, a EU quality certified one. \\
\hline & & \\
\hline & $\begin{array}{l}\text { Not PDO certified } \\
\text { Generic grana cheese }\end{array}$ & $\begin{array}{l}\text { The cheese pack contains a generic grana cheese, that does not } \\
\text { contain a quality certification. }\end{array}$ \\
\hline \multirow[t]{4}{*}{ Price $(€)$} & 2.70 & \multirow[t]{4}{*}{ Purchase price } \\
\hline & 4.10 & \\
\hline & 5.50 & \\
\hline & 6.90 & \\
\hline \multirow{4}{*}{$\begin{array}{l}\text { Nutritional } \\
\text { Certification }\end{array}$} & No label & The cheese pack does not include a nutritional certification. \\
\hline & Nutri-Score & The cheese pack includes a 5-CNL. \\
\hline & NutrInform Battery & $\begin{array}{l}\text { The cheese pack includes the Italian proposed nutritional } \\
\text { certification. }\end{array}$ \\
\hline & Multiple Traffic Light & The cheese pack includes the UK nutritional certification. \\
\hline
\end{tabular}

Source: Elaborated by the authors

\subsection{The RPL model.}

The DCE method is consistent with the random utility theory and the Lancaster theory (Lancaster, 1966) of consumer demand. According to the random utility theory, the utility that individual $n$ derives from product alternative $j$ can be expressed as follows:

$\mathrm{U}_{\mathrm{njt}}=\mathrm{V}_{\mathrm{njt}}+\varepsilon_{\mathrm{njt}}=\beta_{\mathrm{j}} \mathrm{X}_{\mathrm{njt}}+\varepsilon_{\mathrm{njt}}(1)$ 
where $U_{n j}$ is the $n^{\text {th }}$ consumer's utility of choosing product alternative $\mathrm{j}, \mathrm{V}_{\mathrm{njt}}$ is the systematic or representative portion of the utility function that depends on $X_{\mathrm{njt}}$ and $\beta_{\mathrm{n}}$, where $X_{\mathrm{njt}}$ is a vector of product attributes (e.g., 'price', 'FoPL and 'PDO') and $\mathrm{j}$ are the coefficients to be estimated; $\varepsilon_{\mathrm{njt}}$ is the idiosyncratic error and is independently and identically distributed.

In our empirical specification, the utility function includes, as explanatory variables, the product attributes in the choice experiment, as well as an alternative-specific constant $(\alpha)$. The utility function is specified as follows:

Unjt $=\beta_{0}+\beta_{1} \mathrm{PDO}_{n j t}+\beta_{2}$ price $+\beta_{3} \mathrm{FOPL}+\varepsilon_{n j t}(2)$

The alternative-specific constant $\alpha$ enters the model as a dummy variable, taking the value of one for the designed product alternatives (i.e., $\mathrm{A}$ and $\mathrm{B}$ ), and zero otherwise. The 'price' variable represents the different price levels that consumers face in the choice tasks. The ' $P D O$ ' attribute level enter in the model as dummy variables and is coded as one if the cheese has this certification, and zero otherwise. As for the FoPL, the attribute is coded as zero if the cheese has no FoPL label, one if the FoPL was NutriScore, two if it was the NutrInform Battery and three if it was Multiple Traffic Light.

We used the Random Parameter Logit model where for each individual's unique set of preferences and estimates of the utility function.

\section{Results}

\subsection{Sample characteristics}

The participants consisted of 52\% women and $48 \%$ men. There were $20 \%$ of people aged between $35-44$ years old, same percentage was found in the 45-54 years old category. Almost a third of the sample $(29 \%)$ has a low-income level with less than $1500 € /$ month while $39 \%$ of the sample gains between 1500 and 3500 $€ /$ month. When it comes to education level, our sample has almost the same percentage of high-school and university graduates with $43 \%$ of the sample having a high school degree, while $40 \%$ having a university educational level.

Table 2 presents the results for the random parameter logit model. The model is estimated using Nlogit 5.0 Econometric Software, Inc with simulated maximum likelihood, using Halton draws with 500 replications. For each random parameter, the estimated mean and standard deviation are reported. In addition, the estimated standard deviations are significant, indicating heterogeneity in preferences among respondents. The coefficient for the price attribute is significant, and as expected, negative for all products, indicating that a price increase decreases the consumer's utility and therefore this increment would reduce the probability that respondents choose the improved quality attributes in question.

Table 1. Estimation results of the RPL model

\begin{tabular}{|c|c|c|c|}
\hline & Coefficient & Standard Error & $\mathrm{Z}$ \\
\hline \multicolumn{4}{|c|}{\begin{tabular}{l|l} 
CHOICE & \\
Random parameters in utility functions
\end{tabular}} \\
\hline PDO & $2.12541 * * *$ & .18765 & 11.33 \\
\hline NUTRI-SCORE & $.39944 * *$ & .15973 & 2.50 \\
\hline NUTRI_BATTER & $1.47287 * * *$ & .14480 & 10.17 \\
\hline TRAF_LIGHT & $.92225 * * *$ & .11718 & 7.87 \\
\hline \multicolumn{4}{|c|}{ Nonrandom parameters in utility functions } \\
\hline PRECIO & $-.48809 * * *$ & .02517 & -19.39 \\
\hline NO BUY & $-1.84138 * * *$ & .13711 & -13.43 \\
\hline
\end{tabular}




\begin{tabular}{|l|l|l|l|}
\hline NsPDO & $3.12949 * * *$ & .18426 & 16.98 \\
\hline Ns NUTRI-SCORE & $2.72283 * * *$ & .17689 & 15.39 \\
\hline Ns NUTRI_BATTER & $1.86343 * * *$ & .13135 & 14.19 \\
\hline NS TRAF_LIGHT & $1.51845 * * *$ & .11933 & 12.72 \\
\hline NOTE $: * * *, * *, *==>$ Significance at $1 \%, 5 \%, 10 \%$ level. \\
\hline
\end{tabular}

Our RPL model the standard deviations all variables are statistically significant, indicating unobserved heterogeneity in preferences across participants exists. Moreover, the negative sign of the no-buy option shows that consumers earned a higher utility from selecting any alternative than from the no-buy option.

Consumers obtain higher utility from choosing a product with Quality certification and/or a FoPNL rather than a no-buy option. The 'PDO' EU quality certification is positive and statistically significant. In the same line, NUTRI-SCORE, NUTRI_BATTER and,TRAF_LIGHT variables are statistically highly significant. These results suggest that the utility for participants increase when these labels are present on cheese FOPs compared to the baseline (i.e., generic grana cheese or no FoPNL).

The presence of the 'PDO' quality certification on the product was valuated as being the most important attribute followed by the NutrInform label, Multiple Traffic Light and then Nutri-Score. Between all the three investigated FoPNL, Nutri-Score seems to be the label that has the lowest utility, even though it is still positive and statistically significant, meaning that consumers would still prefer a product with NutriScore instead of a product containing no FoPNL at all.

Finally, we also estimate the corresponding willingness to pay for each attributes.

The 'PDO' EU quality certification (Grana Padano cheese) was valued with an additional premium price of $1.15 € /$ package as respect to the no-PDO certification option. Compared to a cheese that has no FoPNL, consumers are willing to pay an extra $0.64 €$ for an option that carries the NutrInform battery, the highest disposition for a FoPNL, in our case, for the Multiple Traffic Light they are ready to pay an extra of $0.51 €$ (a cheese package of 250 grams), and the lowest disposition for FoPNL is attributed to Nutri-Score, 0.22€, always in comparison with a no FoPNL cheese option.

\section{Conclusions}

In this paper we investigate the consumers preferences for labels (FoPNL and 'PDO' quality certification), being interested to find out how are they valued by the Spanish consumers. The results indicate that consumers values positively them. Secondly, the most preferred FoPNL is NutrInform Battery rather than Nutri-Score label, even if the second one is in used in the Spanish food market and it was claimed to be the most effective one. Last but not the least important, is the fact that Grana Padano PDO is preferred to its generic version.

\section{Bibliography}

Galan P., Babio N., Salas-Salvadó J. (2019).’’Nutri-Score: el logotipo frontal de información nutricional útil para la salud pública de España que se apoya sobre bases científicas' '. Nutr Hosp;36(5):1213-1222.

Goiana-da-Silva,F., Cruz-e-Silva.D., Miraldo,M., Calhau,C., Bento,A., Cruz,D., Almeida,F., Darzi,A., Araújo. F. (2019).' Front-of-pack labelling policies and the need for guidance.' The Lancet Public Health, (4), Issue 1, , https://doi.org/10.1016/S2468-2667(18)30256-1.

Julia C, Hercberg S.(2017).', Development of a new front-of-pack nutrition label in France: the 5-Colour Nutri-Score'’. Public Health Panorama ;3:712-25.

Talati,M., Egnell.M, Hercberg.S, Julia.C., Pettigrew,S (2019). "Food Choice Under Five Front-ofPackage Nutrition Label Conditions: An Experimental Study Across 12 Countries". American Journal of Public Health 109, no. 12 (December 1, 2019): pp. 1770-1775, https://doi.org/10.2105/AJPH.2019.30531 